\title{
The Synthesis of Novel Aminoacid Based Amides and Evaluation of Anticancer Effects on Hela Cervical Cancer Cells
}

\author{
Omer Erdogan \\ Department of Biochemistry, Faculty of Medicine, Adnan Menderes University \\ 09010, Aydin, Turkey \\ E-mail: omer.erdogan@adu.edu.tr \\ Giray Topal (Corresponding author) \\ Department of Chemistry, Faculty of Education, Dicle University \\ 21280, Diyarbakir, Turkey \\ E-mail: giray.topal@dicle.edu.tr \\ Yusuf Kurtulmus (Corresponding author) \\ Department of Biochemistry, Faculty of Medicine, Adnan Menderes University \\ 09010, Aydin, Turkey \\ E-mail: yusuf.kurtulmus@adu.edu.tr
}

This research is supported by Adnan Menderes University Teaching Staff Training Program with project number 14043 .

\begin{abstract}
In this study, lysine, phenylalanine, histidine, valine and proline amino acids were reacted with pnitrobenzoyl chloride to give amide derivative compounds. The structure of these compounds was elucidated by FT-IR. The cytotoxic, apoptotic and angiogenic effects of these synthesized compounds were studied in vitro on the HeLa cervical cancer cell line. The cytotoxic activities of 25, 50, 100 and $200 \mu \mathrm{M}$ doses of the synthesized compounds on HeLa cells were determined spectrophotometrically using the WST-I method. B1, B2 and B5 showed cytotoxic effect on HeLa cells whereas B3 and B4 compounds induced proliferation. The amount of poly (ADP-Ribose) Polymerase-I (PARP-I) and vascular endothelial growth factor (VEGF) molecules were measured spectrophotometrically by ELISA method. The PARP-I levels all compounds at all doses were statistically decreased compared to the control group $(\mathrm{p}<0.05)$. The VEGF levels B1, B2 and B5 compounds statistically decreased all doses compared to control whereas $200 \mu \mathrm{m}$ dose of the B4 compound increased compared to the control group
\end{abstract}

Keywords: HeLa, Anticancer, Amides, PARP, VEGF.

\section{Special Issue of Health Sciences}

DOI: $10.7176 / \mathrm{JSTR} / 6-03-36$

\section{Introduction}

Cancer is one of the most important health problems and it is the second most common cause of death in our country after diseases of the cardiovascular system. Among the factors that cause cancer development, include chemical and carcinogenic agents found in cigarette smoke, harmful ultraviolet rays from radiation and sunlight, heavy metal exposure, and physical inactivity. In addition to these harmful factors; Inadequate consumption of vitamins, minerals and antioxidant-rich foods and the weakening of the protective, detoxifying systems and defense mechanisms of the cells against harmful molecules and free radicals also leads to increased cell damage, thereby triggering cancer development (Doll and Peto, 2010; Lombard and Potter, 1950; Hussain et al, 2003; Danaei et al, 2005).

Cervical cancer is the 4th most common cancer in women and 528,000 new cases are diagnosed worldwide each year. The most important risk factor in cervical cancer is human papilloma virus (HPV). However, many environmental factors and hereditary factors that individuals have also play a role in the 
development of cervical cancer. The regression of cervical cancer precursor lesions in some individuals and the development of cancer in some individuals indicate the importance of environmental factors as well as the importance of genetic predisposition in cervical cancer (Globocan, 2012; Burd 2003; Au, 2004; Bosch et al. 1995).

The diagnosis and treatment of cancer, which is a preventable and treatable disease, is of great importance. The most important treatment approach is to destroy cancer cells or control the growth of these cells with chemotherapeutics. Chemotherapy, which is the main strategy used in the fight against cancer, can be used alone or in combination with surgical and radiotherapy approaches. In the clinic, different anticancer drugs are given to patients, alone or in combination, and studies for the discovery of new drugs are also proceed. Chemotherapeutic agents are compounds containing amide, ester, nitrile, hydroxyl, amino, nitro etc. functional groups. Many amide-derived compounds are known to have a toxic, apoptotic and antiangiogenic effect on cancerous cells (Jung et al, 2009; Pradidphol et al, 2012; Alı et al, 2012).

In this study, novel amide-derived compounds were synthesized with p-nitrobenzoyl chloride and amino acids. The cytotoxic, apoptotic and angiogenegic effects of these compounds on HeLa cervical cancer cells were investigated depending on dose and time.

\section{Materials and Methods}

All chemicals and reagents were supplied commercially from Merck and Sigma Aldrich. They were employed in chemical synthesis without any purification or pretreatment. FTIR analysis was obtained in Perkin Elmer Precisely Spectrum One in the scale of $400-4000 \mathrm{~cm}^{-1}$. Each spectrum was collected after 30 scans with $4 \mathrm{~cm}^{-1}$ resolution.

\subsection{The synthesis of Amides}

$5 \mathrm{mmol}$ of aminoacids (lysine, phenylalanine, histidine, valine and proline) and $1.5 \mathrm{~g}$ of sodium acetate were dissolved in $10 \mathrm{~mL}$ of $1 \mathrm{~N} \mathrm{NaOH}$ and stirred for 5 minutes at room temperature. $0.93 \mathrm{~g}(5 \mathrm{mmol})$ of p-nitrobenzoylchloride was added to this solution and, after stirring for $15 \mathrm{~min}$, was filtered. $3 \mathrm{~N} \mathrm{HCl} \mathrm{was}$ added dropwise to the filtered solution until no precipitation was observed. The white solid formed with this process collapsed to the bottom. This precipitate was filtered in a vacuum pump. The obtained solid was crystallized from ethanol (Çakmak et al, 2009). The general structure of synthesized amides (Figure 1) and structure of each compound (Figure 2) were given below.<smiles>[R]C(N)C(=O)NC(=O)c1ccc(NO[C@H]2CC2C)cc1</smiles>

Figure 1: The General Structure of Synthesized Amides

\subsection{Cell Culture Studies}

In this study, HeLa human cervical cancer cells belonging to the American Type Culture Collection (ATCC, Manassas, VA, USA) were used. The cells were cultured in T75 flasks containing DMEM supplemented with $10 \%$ FBS and 1\% penicillin-streptomycin antibiotics suspension and were maintained in a humidified atmosphere, containing $5 \% \mathrm{CO}_{2}$ at $37{ }^{\circ} \mathrm{C}$. The grown cells were removed with the help of $0.05 \%$ Trypsin-EDTA (Sigma T-4049) and passaged (Çıkla et al, 2013; Erdogan et al, 2019). Morphological changes of the cells were checked under an invert microscope (Olympus CK40).

\subsubsection{WST-I Cytotoxicity Assay}

Cells were added to 96-well plates in $100 \mu \mathrm{L}$ medium with 20,000 cells per well. The cells were exposed to incubation for 24 hours. After incubation, $100 \mu \mathrm{L}$ amide concentrations $(25,50,100,200 \mu \mathrm{M})$ were applied to the wells. The cells in the control group were treated with $100 \mu \mathrm{L}$ of $0.1 \%$ DMSO. Plates were incubated for 24,48 and 72 hours. At the end of the incubation periods, $10 \mu \mathrm{L}$ of WST-I reagent was added to the cells in each well, and the cells were incubated for 1 hour. Plates were read on the spectrophotometer at a wavelength of $420 \mathrm{~nm}$. Experiments were studied as 3 replicates independently. The absorbance values obtained were directly related to cell viability (Bunch et al, 2020; Tominaga et al, 1999). 
<smiles>O=C(NCCCCC(NC(=O)c1ccc([N+](=O)[O-])cc1)C(=O)O)c1ccc([N+](=O)[O-])cc1</smiles>

2,6-bis(4-nitrobenzamido) hekzanoik asit-(B1)<smiles>O=C(NC(Cc1ccccc1)C(=O)O)c1ccc([N+](=O)[O-])cc1</smiles>

N-p-Nitrobenzoil-L-phenylalanine(B2)<smiles>CCC(C)C(NC(=O)c1ccc([N+](=O)[O-])cc1)C(=O)O</smiles>

N-p-Nitrobenzoil-L-valin (B4)

N-p-Nitrobenzoil-L-histidin (B3)<smiles>O=C(O)C1CCCN1C(=O)c1ccc([N+](=O)[O-])cc1</smiles>

N-p-Nitrobenzoil-L-prolin (B5)

Figure 2: General structure of synthesized amides

\subsubsection{PARP-I and VEGF}

PARP is a nuclear enzyme with a molecular weight of $116 \mathrm{kDa}$. It is involved in many intracellular molecular events such as DNA damage detection, DNA repair and apoptosis reactions. PARP is the first identified substrate of the caspase. In the process of apoptosis, caspase 3 and caspase 7 break the bond between amino acids Asp214 and Gly215 in the PARP proteina and its divide into two fragments weighing $85 \mathrm{kDa}$ and $25 \mathrm{kDa}$. Thus, the PARP is inactivated, allowing the cell to enter apoptosis (Kim et al, 2005; Smulson et al, 2000).

Vascular endothelial growth factor (VEGF) enables the endothelial cells to increase in number and survive in the newly formed vessel. It also induces angiogenesis by increasing the matrix degrading enzymes such as matrix metalloproteinases. This event is also known to be effective in the growth and development of tumor cells. One of the main approaches in cancer treatment is the development of angiogenesis inhibitors (Xuri et al, 2012; Olofsson et al, 1996; Dvorak et al, 1995).

To measure the amounts of PARP-I and VEGF, a commercial elisa kit was used and all procedures were performed according to the handbook in the kit (FineTest). For this, HeLa cells were seeded in 24-well plates, with 40,000 cells per well. The plate was incubated for 24 hours for the cells to adhere. The media was discarded at the end of the incubation. After the cells were incubated for 24 hours with amide concentrations, they were removed with trypsin and the cells were taken into eppendorf tubes. Cells were washed three times with cold DPBS. $200 \mu \mathrm{L}$ lysis buffer was added to each eppendorf and kept in ice for 30 minutes. During this period, the eppendorf tubes were vortexed at 10-minute intervals. The eppendorf tubes were centrifuged at 13,000 rpm for 10 minutes, the cell lysate was taken to separate ependorphs and stored at $-20^{\circ} \mathrm{C}$ for use in Elisa measurements. 


\subsection{Statistical Analysis}

The statistical analysis of the data obtained was performed using the SPSS (for Windows Release 11.5 Standard Version Copyright (C) Spss Inc. 1989-2001) package program. Whether the groups showed positive or negative correlations related to amide doses was determined using the bidirectional correlation test $(\mathrm{p}<0.05)$.

Cytotoxicity, PARP-I and VEGF data obtained by applying different doses of amides synthesized into HeLa cells were determined to suitability of normal distribution. Statistical analysis of the data was performed using one-way ANOVA and Tukey test as post-hoc. All studies were performed based on $95 \%$ confidence interval $(\mathrm{p}<0.05)$.

\section{Results}

\subsection{FTIR Results of Synthesized Amides}

In the IR spectra, characteristic amide bands are $\mathrm{N}-\mathrm{H}$ and $\mathrm{C}=\mathrm{O}$ stretching vibrations. $\mathrm{OH}$ stretching vibrations in the carboxyl group from the amino acids found in the synthesized amides were interrupted the NH streching vibrations. In compounds B1, B2, B3, B4 and B5, the $\mathrm{C}=\mathrm{O}$ (amide I) stretching vibrations were observed as second characteristic absorption band at $1597 \mathrm{~cm}^{-1}, 1590 \mathrm{~cm}^{-1}, 1599 \mathrm{~cm}^{-1}$, $1598 \mathrm{~cm}^{-1}$, and $1599 \mathrm{~cm}^{-1}$ respectively. The other characteristics bands of synthesized amides in FTIR spectrum were given table 1. In addition, FTIR spectra of all compounds are given supplementary data. These data confirm amide synthesis and are compatible with previous studies (Mallakpour et al. 2014; Kurca et al 2019; Demir et al 2015).

Table 1: The possible FTIR vibrations of synthesized amides

\begin{tabular}{|c|c|c|c|c|c|}
\hline & $\begin{array}{c}\mathrm{C}=\mathrm{O} \text { Strech } \\
\mathrm{cm}^{-1} \text { (Amide) }\end{array}$ & $\begin{array}{l}\mathbf{C}=\mathbf{O} \text { Strech } \\
\mathbf{c m}^{-1} \text { (Ester) }\end{array}$ & $\begin{array}{c}\text { C-N Strech } \\
\mathbf{c m}^{-1}\end{array}$ & $\begin{array}{c}\text { C-O Strech } \\
\text { cm }^{-1}\end{array}$ & $\begin{array}{c}-\mathrm{CH} \text { Bending } \\
\mathbf{c m}^{-1}\end{array}$ \\
\hline B1 & $\begin{array}{l}1597 \\
1642 \\
\end{array}$ & 1695 & 1343 & 1311 & $\begin{array}{l}\mathbf{2 9 3 7} \\
\mathbf{2 8 6 2} \\
\end{array}$ \\
\hline B2 & 1590 & 1688 & 1346 & 1245 & 2820 \\
\hline B3 & 1599 & 1688 & 1348 & 1291 & $\begin{array}{l}2829 \\
2550\end{array}$ \\
\hline B4 & 1598 & 1686 & 1310 & 1276 & $\begin{array}{l}2824 \\
2550 \\
\end{array}$ \\
\hline B5 & 1599 & 1682 & 1346 & 1309 & $\begin{array}{l}2823 \\
2548 \\
\end{array}$ \\
\hline
\end{tabular}

\subsection{The Effect of Amides on Cell Viability}

After 24 hours of incubation, cell viability values at 25, 50, 100 and $200 \mu \mathrm{M}$ amide concentrations were $82.55^{*}, 77.25^{*}, 85.92^{*}$ and 98.51 for compound B-1 respectively, compared to the control group; For compound B-2 86.52*, 89.54*, 107.09* and 109.16*, respectively; For compound B-3, 82.51*, 112.36*, 125.23* and 126.18* respectively; For compound B-4 97.13*, 114.39*, 119.69* and 122.29* respectively; For compound B-5, it was calculated as $98.81,92.44^{*}, 88.59^{*}$ and $83.70^{*}$, respectively (Figure 3). The data obtained in all other doses except B1's $200 \mu \mathrm{M}$ and B5's $25 \mu \mathrm{M}$ dose were found statistically significant $(\mathrm{p}<0.05)$.

After the 48 hours incubation, cell viability values at 25,50,100 and $200 \mu \mathrm{M}$ amide concentrations were $93.21^{*}, 81.76^{*}, 94.21^{*}$ and $111.58^{*}$ for compound B-1 respectively, compared to the control group; 89.45*, 90.36*, 96.37* and 103.72* for compound B-2 respectively; For compound B-3 97.23*, 117.98*, $124.46^{*}$ and 131.37* respectively; For compound B-4, 100.26, 114.09*, 119.71* and 124.46* respectively; For compound B-5, it was calculated as $97.66,91.62^{*}, 85.74^{*}$ and $79.26^{*}$, respectively (Figure 4). The data obtained in all other doses except for the $25 \mu \mathrm{M}$ dose of B4 and B5 were statistically significant $(\mathrm{p}<0.05)$.

After 72 hours of incubation, cell viability values at $25,50,100$ and $200 \mu \mathrm{M}$ amide concentrations were $82.14 * 80.16^{*}, 104.36^{*}$ and $122.5^{*}$ for compound B-1 respectively, compared to the control group; $89.09 *, 99.60,105.08 *$ and $113.49 *$ for compound B-2 respectively; For compound B-3 105.59*, $110.32^{*}, 119.64^{*}$ and $121.43^{*}$ respectively; $77.77^{*}, 89.21^{*}, 93.65^{*}$ and $119.05^{*}$ for compound B-4 respectively; For compound B-5, it was calculated as $97.82,91.43^{*}, 78.17^{*}$ and $69.46^{*}$, respectively (Figure 5). The data obtained in all other doses except for $50 \mu \mathrm{M}$ of B2 and $25 \mu \mathrm{M}$ of B5 were statistically significant $(p<0.05)$. 


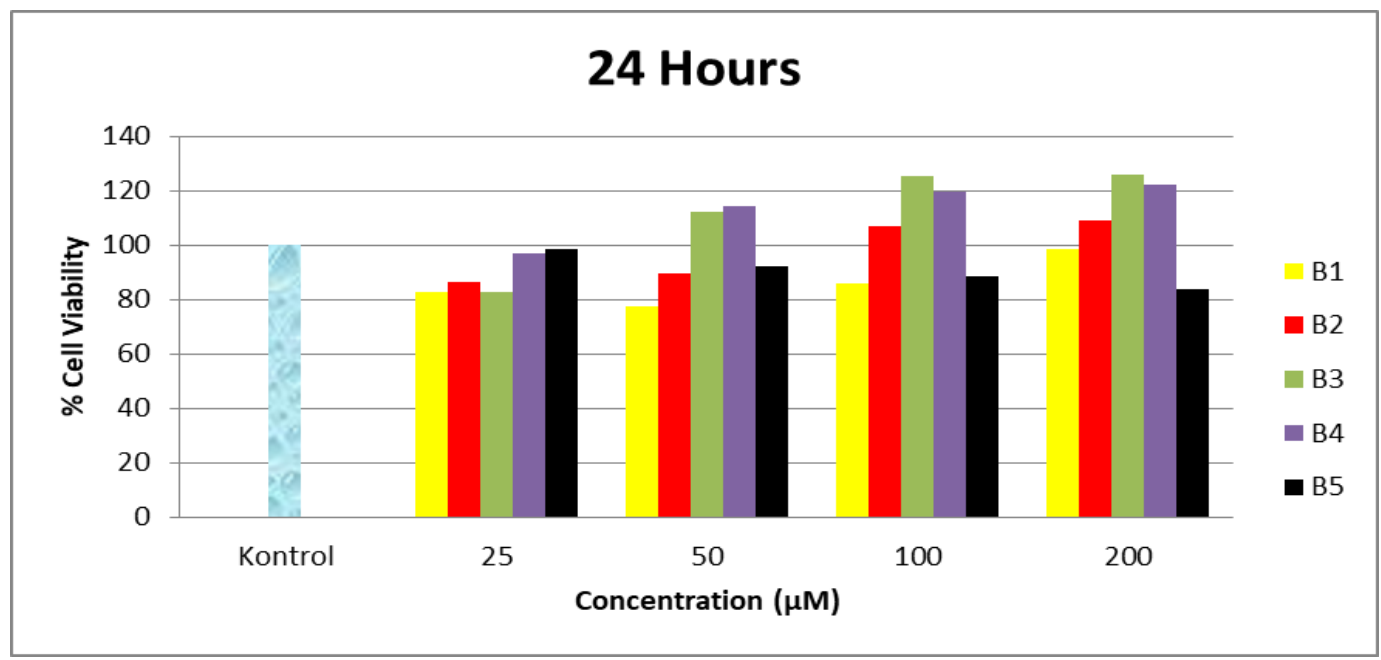

Figure 3: The graphical illustration of dose-dependent $\%$ cell viability after 24 hours incubation.

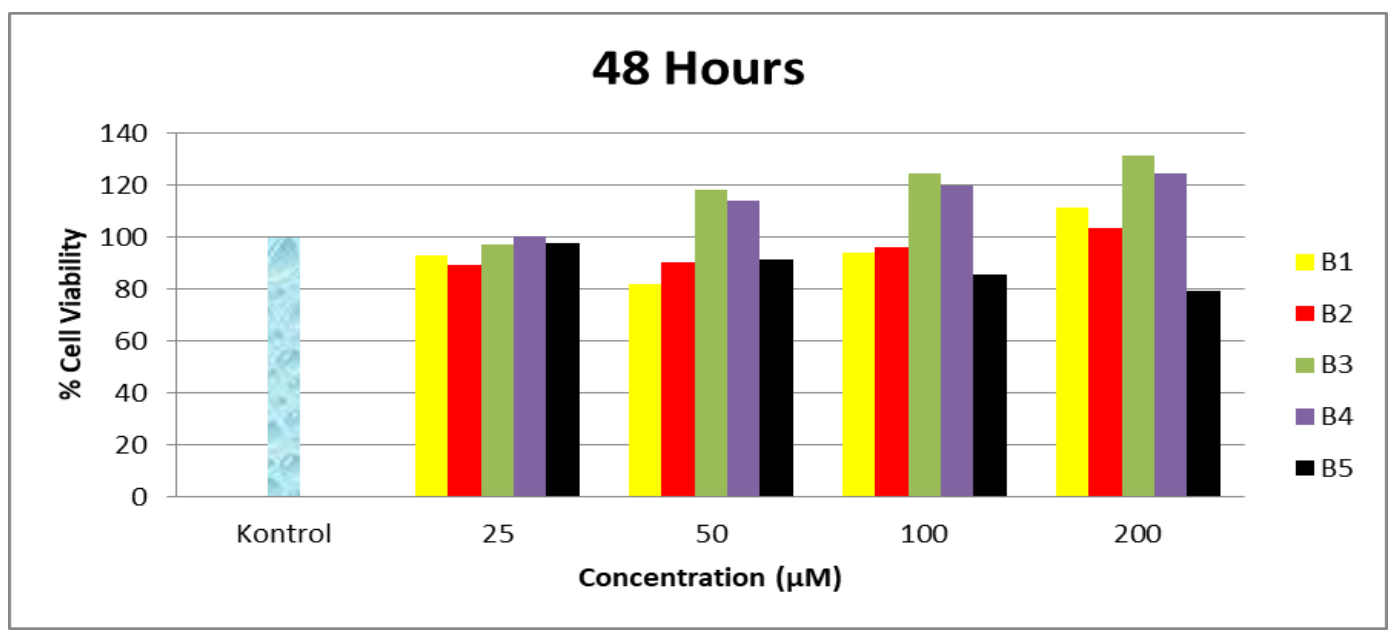

Figure 4: The graphical illustration of dose-dependent $\%$ cell viability after 48 hours incubation

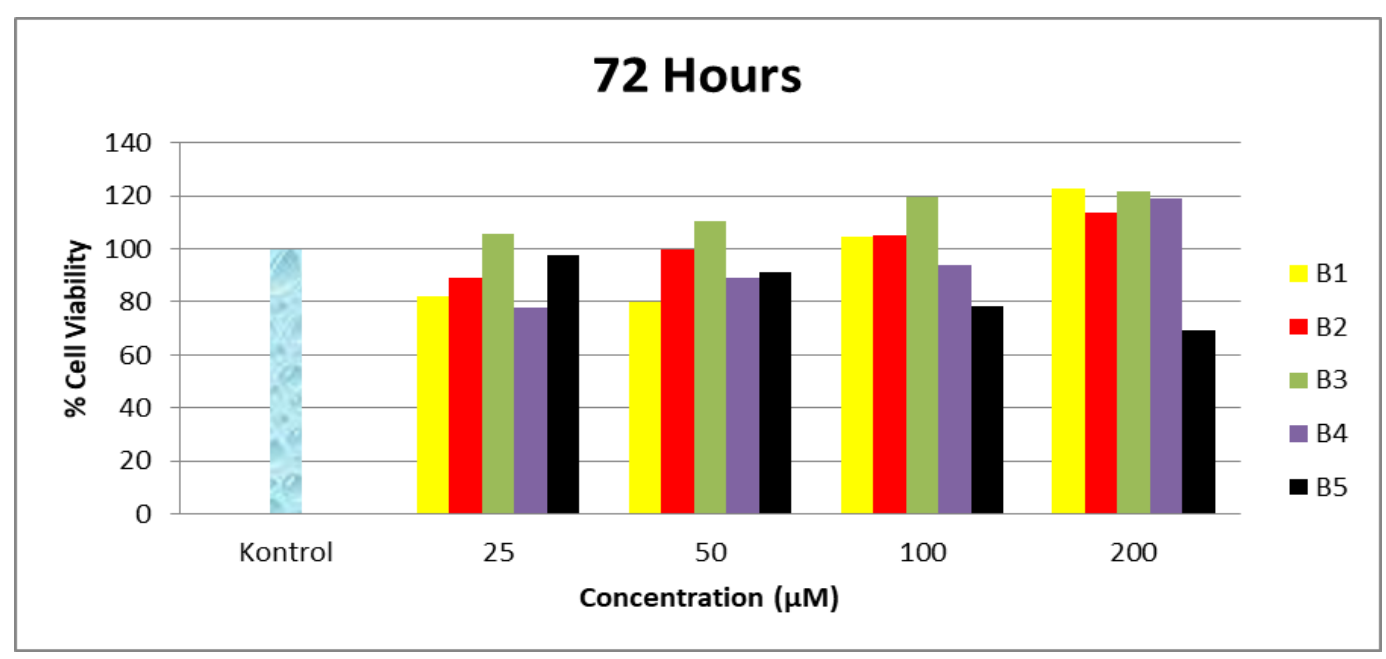

Figure 5: The graphical illustration of dose-dependent $\%$ cell viability after 72 hours incubation 


\subsection{The Effect of Synthesized Amides on Apoptosis}

At the end of the 24-hour incubation, the amount of PARP-I (ng) at 25, 50, 100 and $200 \mu \mathrm{M}$ amide concentrations was $1.46^{*}, 0.99 *, 1.25^{*}$ and $1.16^{*}$ for B-1 compound, respectively; For compound B-2 $1.46^{*}, 1.32^{*}, 2.31^{*}$ and $1.78^{*}$, respectively; $0.70^{*}, 0.69^{*}, 2.12^{*}$ and $0.96^{*}$ for compound $\mathrm{B}-3$, respectively $1.36^{*}, 0.82^{*}, 1.19^{*}$ and $2.41^{*}$ for compound 4 ; For compound B-5, it was calculated as $2.27^{*}, 2.47^{*}, 2.84^{*}$ and $1.44^{*}$, respectively. PARP-I amount of the control group was measured $4.14 \mathrm{ng}$. (Figure 6). The data obtained at all doses were statistically significant compared to the control group (p $<0.05)$.

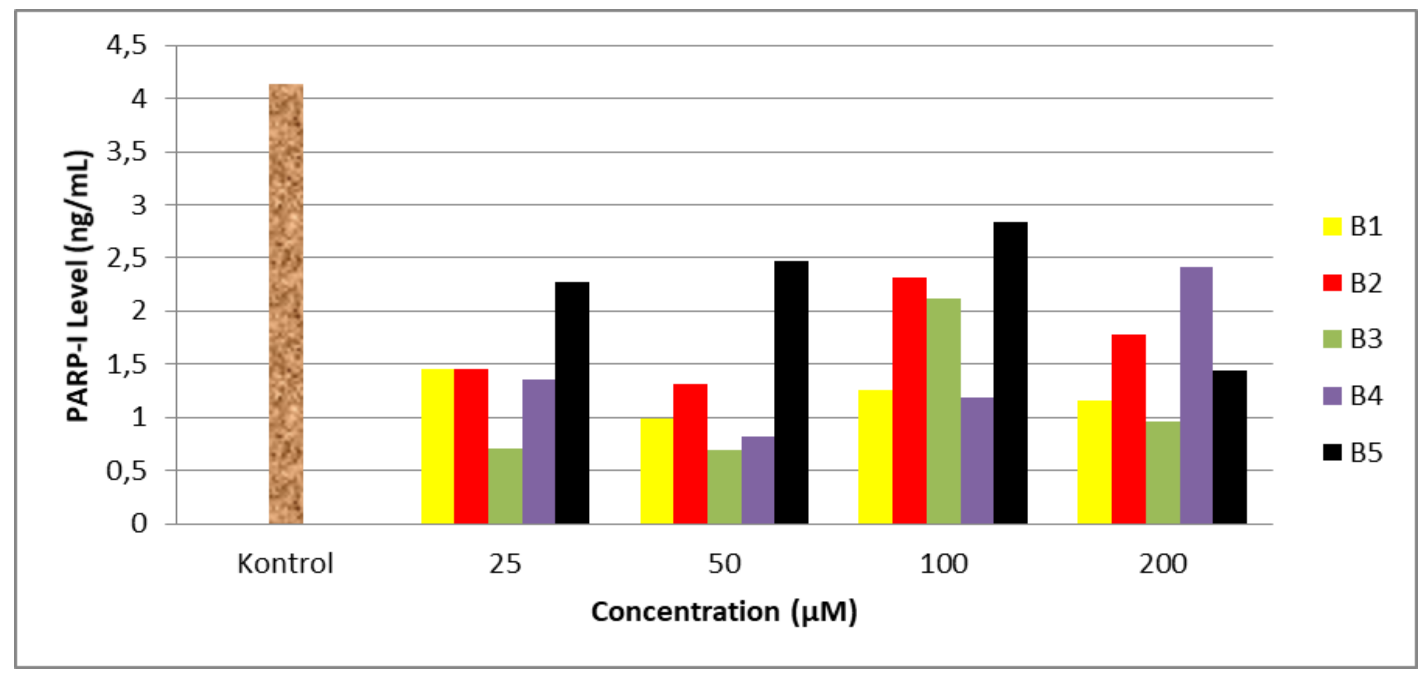

Figure 6: The graphical illustration of dose-dependent PARP-I levels of HeLa cell lysate

\subsection{The Effect of Synthesized Amides on Angiogenesis}

After 24 hours of incubation, the amount of VEGF (pg) at 25, 50, 100 and $200 \mu \mathrm{M}$ amide concentrations was 527.27, 491.39*, 393.42* and 289.36* for compound B-1, respectively; 275.07*, 389.73*, 369.23* and 582.28* for compound B-2, respectively; For compound B-3, 515.39*, 323.21*, 232.84* and 788.44*, respectively; For compound B-4, 395.27*, 309.41*, 382.31* and 363.57*, respectively; For compound B-5, it was calculated as 565.77, 505.14*, 391.58* and $215.27^{*}$, respectively. The control group's VEGF amount was measured as 543.75 pg (Figure 7). Data obtained in all other doses except for $25 \mu \mathrm{M}$ doses of B1 and B5 were found statistically significant $(\mathrm{p}<0.05)$.

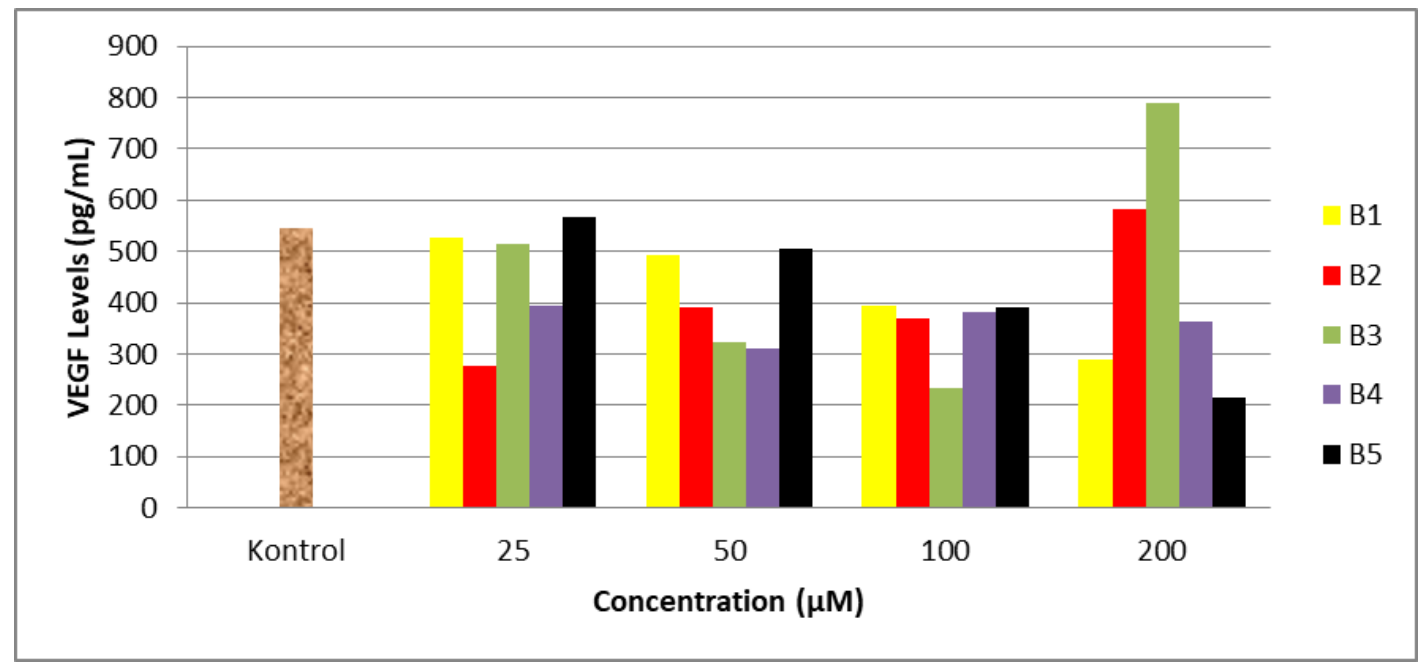

Figure 7: The graphical illustration of dose-dependent VEGF levels of HeLa cell lysate 


\section{Discussion}

Like other types of cancer, there are some disadvantages for cervical cancer such as current chemotherapeutics having undesirable side effects and metabolism developing drug resistance over time, so scientists concentrate on developing new chemotherapeutics. The main treatment approach to be done with chemotherapeutics is to induce apoptosis and prevent metastasis by suppressing vascularity. Many studies have been reported on this treatment approach today (Abbas et al, 2020; Zhong et al, 2020; Taylor et al, 2019; Gagic et al, 2016).

In this study, the chemotherapeutic effects of amides synthesized by our research team were investigated on HeLa cervical cancer cells. Among the synthesized compounds; B1, B2 and B5 had cytotoxic effects on HeLa cells; Compounds B3 and B4 were found to show proliferative effects. The B1 and B2 compounds have a more modest cytotoxic effect than current chemotherapeutics. It is hoped that the new organo-metallic derivatives of these compounds to be synthesized with metal atoms will show better activity. Compounds B3 and B4 can be used alone or as a supplement to currently used drugs to create tumors or develop tumors in in vivo studies due to their proliferative effect.

\section{References}

Abbas, S. et al. (2020). Anticancer evaluation of a Manganese Complex on HeLa and MCF-7 Cancer Cells: Design, Deterministic Solvothermal Synthesis Approach, Hirshfeld analysis, DNA Binding, Intracellular Reactive Oxygen Species (ROS) Production, Electrochemical Characterization and Density Functional Theory. Journal of Biomolecular Structure and Dynamics. In press.

Alı R et al. (2012). New Anticancer Agents: Recent Developments in Tumor Therapy. Anticancer Research. 32(7). 2999-3005.

Au, W.W. (2004). Life style, environmental and genetic susceptibility to cervical cancer. Toxicology. $198,117-120$.

Bosch, F.X. et al. (1995). Prevalence of Human Papillomavirus in Cervical Cancer: a Worldwide Perspective. Journal of the National Cancer Institute. 87(11), 796-802.

Bunch, H. et al. (2020). Evaluating cytotoxicity of methyl benzoate in vitro. Heliyon. 6(2), e03351.

Burd E.M. (2003). Human Papillomavirus and Cervical Cancer. Clinical Microbiology Reviews. 16(1), 1-17.

Çakmak R. et al. (2009) Resolution of ( \pm )- $\beta$-methylphenylethylamine by a novel chiral stationary phase for Pirkle type column chromatography. Chirality. 22, 252-257.

Çıkla, P. et al. (2013). Synthesis, cytotoxicity, and pro-apoptosis activity of etodolac hydrazide derivatives as anticancer agents. Arch Pharm. 346(5), 367-379.

Danaei, G. et al. (2005). Causes of cancer in the world: comparative risk assessment of nine behavioural and environmental risk factors. The Lancet. 366(9499), 1784-1793.

Dvorak, H.F. et al. (1995). Vascular permeability factor/vascular endothelial growth factor, microvascular hyperpermeability, and angiogenesis. American Journal of Pathology. 146(5), 1029-1039.

Demir, S. et al. (2015). A novel 3-acetoxy-2-methyl-465 N-(4-methoxyphenyl) benzamide: Molecular structural describe, antioxidant activity 466 with use X-ray diffractions and DFT calculations, J. Mol. Struct. 1100, 582-591.

Doll R., Peto R. (1981). The causes of cancer: quantitative estimates of avoidable risks of cancer in the United States today. Journal of The National Cancer Institute. 66 (6), 1191-1308. 
Erdogan, O. et al. (2019). Enginar yaprağı sulu ekstraktı kullanılarak çinko oksit nanopartiküllerinin yeşil sentezi, karakterizasyonu, anti-bakteriyel ve sitotoksik etkileri. Düzce Medical Journal. 21(1), 19-26.

Gagic Z. et al. (2016). Synthesis of the vitamin E amino acid esters with an enhanced anticancer activity and in silico screening for new antineoplastic drugs. European Journal of Pharmaceutical Sciences. 88, 59-69.

Hussein S.P. et al. (2003). Radical causes of cancer. Nature Reviews Cancer. 3, 276-285.

Jung, M. et al. (2009). Synthesis and anticancer activity of novel amide derivatives of non-acetal deoxoartemisinin. Bioorganic \& Medicinal Chemistry Letters.19, 6303-6306.

Kırca BK. et al. (2019). Two new benzamides: Synthesis, spectroscopic characterization, X-ray diffraction, and electronic structure analyses. Journal of molecular structure. Preprint.

Kim M.Y. et al. (2005). Poly(ADP-ribosyl)ation by PARP-1: PAR-laying NAD+ into a nuclear signal. Genes Dev. 19, 1951-1967.

Lombard H.L. and Potter E.A. (1950). Epidemiological aspects of cancer of the cervix. II. Hereditary and environmental factors. Cancer. 3(6). 960-968.

Mallakpour, S. and Zadehnazari A. (2014). Molten salt-supported polycondensation of optically active diacid monomers with an aromatic thiazole-bearing diamine using microwave irradiation. Journal of Advanced Research. 5, 311-318.

Olofsson, B. et al. (1996). Vascular endothelial growth factor B, a novel growth factor for endothelial cells. PNAS. 93(6), 2576-2581.

Pradidphol, N. et al. (2012). First synthesis and anticancer activity of novel naphthoquinone amides. European Journal of Medicinal Chemistry. 49, 253-270.

Smulson M.E. et al. (2000) Roles of poly(ADP-ribosyl)ation and PARP in apoptosis, DNA repair, genomic stability and functions of P53 and E2F-1. Adv. Enzyme. Regul. 40, 183-215.

Taylor, W.F. et al. (2019). 7-epi-Clusianone, a Multi-Targeting Natural Product with Potential Chemotherapeutic, Immune-Modulating, and Anti-Angiogenic Properties. Molecules. 24(23), 4415 .

Tominaga, H. et al. (1999) A water-soluble tetrazolium salt useful for colorimetric cell viability assay. Anal. Communication. 36, 47-50.

WEB_1. (2012). Globocon's web site. http://globocan.iarc.fr/Default.aspx. (21.01.2020).

Xuri, L. et al. (2012). Complicated life, complicated VEGF-B. Trends in Molecular Medicine. 18(2), 119-127.

Zhong, Y. et al. (2019). Design, synthesis and evaluation of phthalazinone thiohydantoin-based derivative as potent PARP-1 inhibitors. Bioorganic chemistry. 91, 103181. 